\title{
Empirical Models for End-Use Properties Prediction of LDPE: Application in the Flexible Plastic Packaging Industry
}

\author{
Maria Carolina Burgos Costa*, André Luiz Jardini, Maria Regina Wolf Maciel, \\ Marcelo Embiruçu ${ }^{\mathrm{b}}$, Rubens Maciel Filho ${ }^{\mathrm{a}}$ \\ ${ }^{a}$ Faculdade de Engenharia Química, Universidade Estadual de Campinas - UNICAMP \\ CP 6066, 13080-970 Campinas, SP - Brazil \\ ${ }^{\mathrm{b}}$ Escola Politécnica da Universidade Federal da Bahia - Salvador, BA - Brazil
}

Received: March 17, 2007; Revised: March 3, 2008

\begin{abstract}
The objective of this work is to develop empirical models to predict end use properties of low density polyethylene (LDPE) resins as functions of two intrinsic properties easily measured in the polymers industry. The most important properties for application in the flexible plastic packaging industry were evaluated experimentally for seven commercial polymer grades. Statistical correlation analysis was performed for all variables and used as the basis for proper choice of inputs to each model output. Intrinsic properties selected for resin characterization are fluidity index (FI), which is essentially an indirect measurement of viscosity and weight average molecular weight (MW), and density. In general, models developed are able to reproduce and predict experimental data within experimental accuracy and show that a significant number of end use properties improve as the MW and density increase. Optical properties are mainly determined by the polymer morphology.
\end{abstract}

Keywords: modeling, end use property, intrinsic property, polyethylene

\section{Introduction}

Nowadays polyethylene (PE) blow film is one of the most important polymeric products. PE film manufacturers have been aggressive in improving film properties and reducing production cost so that they can be more competitive in the global market. Information concerning blown film structure and structure-property relationship is important to PE film manufacturers. The study of film structure can provide the knowledge about the structural formation process during film blowing and, in turn, the effect of processing conditions on film properties ${ }^{1}$.

In the film blowing process, the molten polymer is extruded through an annular die and the air is forwarded from the center of die to form a bubble. The molten tube leaving the die is stretched upwards by the nip rolls, at the same time cooling is performed through an air ring which directs air to the outside surface of the bubble and thus affecting closely molecular relaxation and crystallinity. Figure 1 illustrates a scheme of the blown film process.

Resins produced in a polymerization process are approved by industrial quality control routines only if they meet a package of specifications needed for certain applications. Specifications are usually defined in terms of end use properties. If resin properties do not meet the defined specifications, resin lots are discarded, reprocessed or used for other applications, bringing some disadvantage to the process economy ${ }^{2,3}$. Therefore, the development of mathematical relationships to allow the prediction of end use properties of polymer resins as functions of the polymerizations conditions may be very useful for the production of resins with assured specified properties. The intention is to optimize the operational conditions of transformation systems, resulting in better products with lower costs. Deep knowledge about correlations between end use properties (regarding to resulting properties of the product obtained in the polymer production industries) and polymer intrinsic properties could be a possible way to define the operational conditions of each processing unit in the industry in order to achieve the desired properties. Mathematical models are of paramount importance for polymerization engineering, as final polymer properties, and process responses depend upon the process operation conditions in a very complex and nonlinear manner ${ }^{4,5}$.

It is always welcome to be able to develop relationships or correlations taking into account the intrinsic polymer properties as morphology, orientation, and residual stresses. However, for the easy to use industrial implementation it is helpful to have correlations based properties that are easier to measure. Properties as fluidity index (FI) and density may be used to identify the main polymer characteristics, useful for the polymer production industries, even as an early state of the polymer manufacturer process. In order to become the procedure more general and able to be used in industrial conditions in which on line properties measurement are important source of information to interfere in the process aiming to obtain the product with the desired characteristics, fluidity index and density are good candidates as monitored properties.

The objective of this work is to develop empirical models able to predict end use properties of LDPE resins as functions of intrinsic properties of the polymer resins. The development was carried out through resins characterizations and variable determination used on empirical models. The end use properties selected for empirical models development are usually required by customers of the flexible plastic packaging industries.

\section{Experimental Study}

In this work, seven industrial resin grades of LDPE are studied. The most important properties for resins applied in the plastic packaging industry were considered and experiments involving those resins properties were evaluated. Such properties are: ultimate tensile strength (UTS), yield strength (YS), elongation at break (EB), stiffness, vicat softening point (VP), melting temperature (Tm), crystallization temperature (Tc), ultimate tensile strength (MD), ultimate 


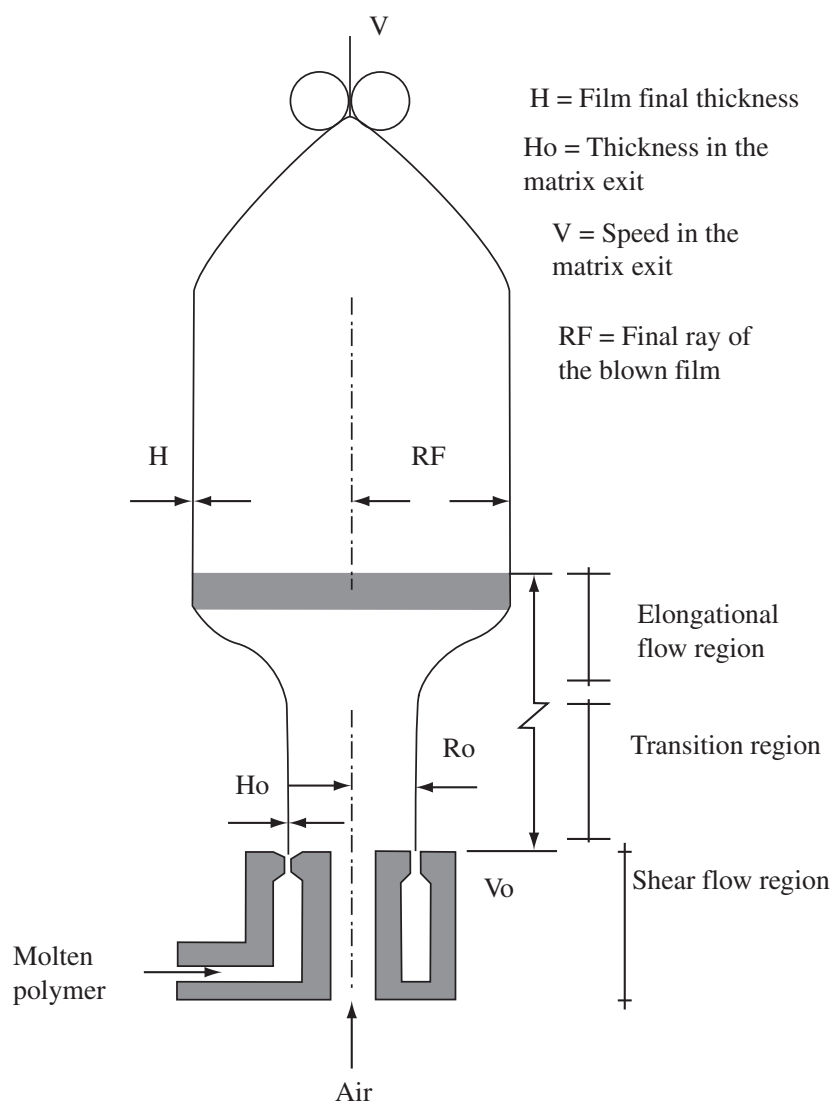

Figure 1. Scheme of the blown film process.

tensile strength (TD), yield strength (MD), yield strength (TD), dart impact strength (DIS) and film optical properties such as, haze and gloss. After molding of the samples, analyses were performed. For the cases in which the preservation was required, samples had been kept in the following conditions: $(23 \pm 2){ }^{\circ} \mathrm{C}$ and $(50 \pm 5) \%$ of relative humidity, for minimum time of 40 hours before the test.

A data treatment was made and empirical models correlating end use and intrinsic properties were developed, as showed in Figure 2. This was carried out through STATISICA software as it follows: some important correlations between all properties were found through correlations tables and then the chosen inputs for the models were: fluidity index (FI) and density. Among several properties, the fluidity index and density are those relatively easy to measure and, as they exert a significant influence in the final polymer, it is convenient to use them as a basis for model development. Thus, using a set of experiments it was possible to built-up correlations expressing for instance performance properties (end use properties as tensile strength) as function of density and FI. Subsequently, the empirical models were built up for the most usual end use properties.

The fluidity index (FI) is an indication of the polymer flow properties in low shear rates. The flow rates determination consists of an automatic register of the time necessary to extruder a specific volume of polyethylene through an orifice. The weight used was $6480 \mathrm{~g}$, followed by the weight of $2160 \mathrm{~g}$. The extrusion time, volume, temperature and the molten polymer density were used to calculate the FI. The equipment used for measurement of FI was a Tinus Olsen Plastometer.

The polyethylene density is determined by the measured of its mass in distilled water. The density is calculated using the "Principle of Archimedes". The Principle of Archimedes states that a floating body is buoyed up by the weight of liquid it displaces. Consequently,

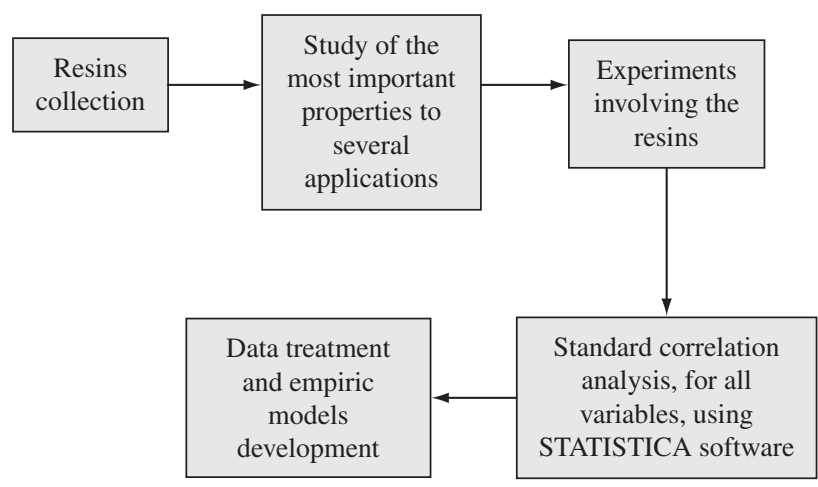

Figure 2. Schematic diagram of experimental procedure.

an object floating in a liquid denser than water will not be submerged to the same extent as in water. The equipment used to determine the density was a Toyoseiki Areometer, model D-1. The end use properties were determined in accordance to specific analysis methods, normally used by the resin suppliers which are based on standard methods as described below.

Tensile mechanical properties were determined in accordance with the ASTM D638-03 norm. This standard ASTM method was used because the correlations between end use properties and intrinsic properties were determined in order to result in properties of the product obtained in the polymer production industries, before its transformation. The ultimate tensile strength is the maximum resistance to fracture. It is equivalent to the maximum load that can be carried by one square inch of cross-sectional area when the load is applied as simple tension. Tensile strength is the ratio between the maximum load and the area of original cross section.

A number of terms have been defined for the purpose of identifying the stress at which plastic deformation begins. The value most commonly used for this purpose is the yield strength. The yield strength is defined as the stress at which a predetermined amount of permanent deformation occurs. The graphical portion of the early stages of a tension test is used to evaluate yield strength. To find out yield strength, the predetermined amount of permanent strain is set along the strain axis of the graph, to the right of the origin (zero).

The elongation at break of a material is the percentage increase in length that occurs before it breaks under tension. Elongation at break values of several hundred percent are common for elastomers and film/packaging polyolefins. Rigid plastics often exhibit values under $5 \%$. The combination of high ultimate tensile strength and high elongation at break leads to materials of high toughness.

The stiffness was determined in accordance with the ASTM D742-02 norm, procedure A, in an Instron instrument, model 5565. Five injection molded test pieces were used for each resin, with thickness of $3 \mathrm{~mm}$, width of $12.5 \mathrm{~mm}$ and length of $200 \mathrm{~mm}$. Samples were deformed until a total deflection of $3 \mathrm{~mm}$.

The vicat softening point was determined in accord to the ASTM D1525-00 norm. This property is the temperature at which a flat-ended needle penetrates the specimen to the depth of $1 \mathrm{~mm}$ under a specific load. The temperature reflects the point of softening to be expected when a material is used in an elevated temperature application. A test specimen is placed in the testing apparatus so that the penetrating needle rests on its surface at least $1 \mathrm{~mm}$ from the edge. A load of $10 \mathrm{~N}$ or $50 \mathrm{~N}$ is applied to the specimen. The specimen is then lowered into an oil bath at 23 degrees ${ }^{\circ} \mathrm{C}$. The bath is raised at a rate of $50^{\circ}$ or $120^{\circ} \mathrm{C}$ per hour until the needle penetrates $1 \mathrm{~mm}$.

Melting temperature and crystallization temperature were determined in accord to the ASTM D3895-02 norm. The thermal proper- 
ties were measured using a differential scanning calorimeter (Perkin Elmer, DSC-7). In this technique, there are two pans. In one pan, is put the polymer sample, and the other one is the reference pan. Each pan sits on top of a heater. The computer turns on the heaters, and heats the pans at a specific rate, usually something like $10{ }^{\circ} \mathrm{C}$ per minute. Degree of crystallinity was evaluated from DSC measurements as the ratio between the amount of heat required to melt the sample and the heat of fusion for $100 \%$ crystalline PE.

The tensile properties of the films were determined in accord to the ASTM D882-02 norm. The engineering stress-strain curves of the blown films were obtained using a screw-driving mechanical testing machine (Instron, Model 5565) at ambient conditions $\left(23 \pm 2{ }^{\circ} \mathrm{C}\right.$ and $50 \pm 5 \%$ of relative humidity). To obtain engineering stress-strain curves, specimens with dimensions of $50 \times 10 \mathrm{~mm}$ were stretched at a cross-head speed of $50 \mathrm{~mm} / \mathrm{min}$ either to breaking or to the limit of the instrument.

The dart impact strength of all the blown films was measured according to ASTM D1709-01 (method A). Impact strength measures the amount of energy that a material can absorb without to tear. High molecular weight resins are very tough since they absorb more energy than lower molecular weight resins.

The optical appearance properties of a polymer, such as haze and gloss, have no (direct) correlation with its chemical structure; they are largely determined by physical factors. Gloss was measured according to ASTM D2457-97 norm. The equipment utilized for gloss measurement was a BYK - GARDNER Micro - gloss $45^{\circ}$.

Haze is correlated with characteristics and processing of the resin. This property was determined in accord to the ASTM D1003-00. The method determinate the light dispersion measurement as it passes through of a transparent film. The results are more homogeneous in the surfaces with less internal imperfection, because the fact allows the light diffusion increase. Optical properties are important for quality control and application of the resins and the equipment utilized was a Haze - Gard Plus, Model 4725.

Tables 1 and 2 show the normalized experimental results obtained for resins utilized in this study. The experimental data of the properties were normalized and representative empirical models are showed. Thus, the model parameters were found in such way that each end use property is connected to the intrinsic properties (used as entrance variable in the models).

\section{Results and Discussion}

In order to obtain more comprehensive model structures, a good approach is to develop models as simpler as possible. The idea is to make easier to solve and to use models that enable a suitable representation of complex systems. Otherwise, the development of fully detailed deterministic models is a hard task requiring most of the times molecular modeling approaches which are not either readily available and precise or too expensive due to large computer burden needed to run the software. At this point, is important to mention that it was not found in either in literature or commercial software a working tool able to deal with complex molecules as high molecular weight PE.

After characterization of the resins used as case study, the construction of the models was developed using statistical tools, as factorial design and experimental planning, through the commercial software Statistica. Tables 3 and 4 illustrate the determination coefficient $\mathrm{R}^{2}$, the parameters values found for each model and the satatistic correlation coefficient "p" for each parameter. For most of the equations, the higher " $p$ "assumed was the standard deviation normally used which is 0.05 . It signifies that the probability of a calculated value for a correlation factor (or for a parameter) becomes repeatable in further experiments (or data sets) are either higher than or equal to $95 \%$. However, in specific case of some properties, the considered " $p$ " was a little higher than 0.05 , since a satisfactory multiple correlation coefficient of the model is assumed. It is important to point out that models presented here were build-up with normalized parameters. Subsequently, the predictions from the empirical models were compared to the experimental values. Figures 3-10 illustrate the performance of the empirical models which, in fact, is quite satisfactory. It is possible to conclude that the empirical models developed may be useful to be used in either product development or for the definition of operation strategy to obtain the products with the desired properties.

Table 1. Experimental values of resins.

\begin{tabular}{ccccccccccc}
\hline Resin & FI & Density & UTS & YS & EB & Stiffness & VP & Tm & Tc \\
\hline RFB-1 & 0.006 & 0.550 & 1.000 & 0.550 & 0.933 & 0.065 & 0.875 & 0.430 & 0.400 \\
RFB-2 & 0.041 & 0.520 & 1.000 & 0.375 & 0.880 & 0.034 & 0.625 & 0.490 & 0.367 \\
RFB-3 & 0.014 & 0.575 & 0.900 & 0.325 & 0.873 & 0.139 & 0.625 & 0.500 & 0.333 \\
RFB-4 & 0.283 & 0.610 & 0.286 & 0.250 & 0.850 & 0.156 & 0.375 & 0.560 & 0.189 \\
RFB-5 & 0.297 & 0.950 & 0.386 & 0.875 & 0.167 & 0.990 & 0.500 & 0.900 & 0.922 \\
RFB-6 & 0.221 & 0.500 & 0.557 & 0.300 & 1.000 & 0.086 & 0.375 & 0.380 & 0.311 \\
RFB-7 & 1.000 & 0.400 & 0.143 & 0.050 & 0.493 & 0.049 & 0.125 & 0.090 & 0.067 \\
\hline
\end{tabular}

Table 2. Experimental values of resins (continuation).

\begin{tabular}{|c|c|c|c|c|c|c|c|}
\hline Resin & UTS (MD) & UTS (TD) & YS (MD) & YS (TD) & DIS & Haze & Gloss \\
\hline RFB-1 & 0.971 & 1.000 & 0.500 & 0.200 & 0.983 & 0.771 & 0.050 \\
\hline RFB-2 & 0.786 & 0.786 & 0.325 & 0.180 & 0.510 & 0.636 & 0.231 \\
\hline RFB-3 & 0.757 & 0.929 & 0.400 & 0.220 & 0.719 & 0.971 & 0.008 \\
\hline RFB-4 & 0.786 & 0.821 & 0.402 & 0.340 & 0.356 & 0.186 & 0.912 \\
\hline RFB-5 & 0.286 & 0.429 & 0.900 & 0.940 & 0.004 & 0.914 & 0.035 \\
\hline RFB-6 & 0.714 & 0.857 & 0.287 & 0.160 & 0.312 & 0.014 & 0.988 \\
\hline RFB-7 & 0.0714 & 0.0357 & 0.080 & 0.046 & 0.042 & 0.643 & 0.377 \\
\hline
\end{tabular}


Table 3. Parameters of ultimate tensile strength, yield strength, elongation at break, stiffness, vicat softening point, melting temperature and crystallization temperature models.

\begin{tabular}{|c|c|c|}
\hline \multicolumn{3}{|c|}{ Ultimate tensile strength $\left(\mathrm{R}^{2}=0.960\right)$} \\
\hline Independent variable & Parameter & "p" \\
\hline FI & -0.176352 & 0.000594 \\
\hline Independent parameter & 0.190533 & 0.000000 \\
\hline \multicolumn{3}{|c|}{ Yield strength $\left(\mathrm{R}^{2}=0.883\right)$} \\
\hline Independent variable & Parameter & "p" \\
\hline Density & 1.327764 & 0.008376 \\
\hline Independent parameter & -0.389353 & 0.010346 \\
\hline \multicolumn{3}{|c|}{ Elongation at break $\left(\mathrm{R}^{2}=0.952\right)$} \\
\hline Independent variable & Parameter & "p" \\
\hline FI & -0.63435 & 0.009822 \\
\hline Density & -1.43731 & 0.006337 \\
\hline Independent parameter & 1.75388 & 0.005634 \\
\hline \multicolumn{3}{|c|}{ Stiffness $\left(\mathrm{R}^{2}=0.988\right)$} \\
\hline Independent variable & Parameter & "p" \\
\hline FI & 0.27123 & 0.027349 \\
\hline Density & 2.02570 & 0.000223 \\
\hline Independent parameter & -1.04289 & 0.000240 \\
\hline \multicolumn{3}{|c|}{ Vicat softening point $\left(\mathrm{R}^{2}=0.961\right)$} \\
\hline Independent variable & Parameter & "p" \\
\hline FI & -0.121312 & 0.002457 \\
\hline Density & 0.373701 & 0.081809 \\
\hline Independent parameter & -0.007840 & 0.082220 \\
\hline \multicolumn{3}{|c|}{ Melting temperature $\left(\mathrm{R}^{2}=0.987\right)$} \\
\hline Independent variable & Parameter & "p" \\
\hline FI & -0.205253 & 0.024532 \\
\hline Density & 1.202995 & 0.000501 \\
\hline Independent parameter & -0.172340 & 0.001202 \\
\hline \multicolumn{3}{|c|}{ Crystallization temperature $\left(\mathrm{R}^{2}=0.933\right)$} \\
\hline Independent variable & Parameter & "p" \\
\hline FI & -0.023585 & 0.041018 \\
\hline Density & 1.439193 & 0.006941 \\
\hline Independent parameter & -0.530268 & 0.012888 \\
\hline
\end{tabular}

\subsection{Ultimate tensile strength, yield strength, elongation at break and stiffness}

Ultimate tensile strength (UTS) presents negative correlation with the fluidity index (FI), according to the model equation. This means that the ultimate tensile strength increases as fluidity index decreases and molecular weight increases. This probably occurs because the increase of molecular weight leads to a larger number of tie chains; thus the materials become physically more interconnected. This means that the applied load becomes less concentrated in points among the microfibrils surfaces. The number of connections has a stronger effect under the failure resistance (in comparison to the microfibril size), because the failure is preferably initiated over the microfibril border. The density did not exert a significant influence in the ultimate tensile strength. Equation 1 presents the best model obtained here.

$$
\mathrm{UTS}=\mathrm{a} * \ln (\mathrm{FI})+\mathrm{b}
$$

It is well known from the literature that the yield strength (YS) depends strongly on the polymer density. This fact is justified by stronger interaction forces between molecules as the density increases.
Kundu et al. ${ }^{6}$ showed the influence of various film preparation procedures on the crystallinity, morphology and mechanical properties of pure linear low density polyethylene. According to them, quenching of films reduces the degree of cristallinity whereas natural cooling allows crystals to grow to a stacked lamellar structure or to a higher spherulite embedded in lamellar structure and hence increases in cristallinity. The increase in crystalinity induces the increase in yield stress for films cooled at room temperature. Yield strength didn't present considerable dependence with the fluidity index. The best modeling results were obtained with a simple straight, as shown in Equation 2.

$$
\text { YS * density }+b
$$

Elongation at break (EB) presents negative correlation with the density. The presence of long branches causes the increase of the polymer toughness. In the proposed model the elongation at break decreases as the FI increases. Large molecular chains and long branches can be stretched and straightened. Moreover, the number of intercrystalline chains linking the microfibrils increases with 
Table 4. Parameters of ultimate tensile strength (MD), ultimate tensile strength (TD), yield strength (MD), yield strength (TD), dart impact strength, haze and gloss models.

\begin{tabular}{|c|c|c|}
\hline \multicolumn{3}{|c|}{ Ultimate tensile strength $(\mathrm{MD})\left(\mathrm{R}^{2}=0.863\right)$} \\
\hline Independent variable & Parameter & "p" \\
\hline FI & -0.798006 & 0.012325 \\
\hline Independent parameter & 0.836610 & 0.000003 \\
\hline \multicolumn{3}{|c|}{ Ultimate tensile strength $(\mathrm{TD})\left(\mathrm{R}^{2}=0.919\right)$} \\
\hline Independent variable & Parameter & "p" \\
\hline FI & -0.906179 & 0.003421 \\
\hline Independent parameter & 0.934752 & 0.000001 \\
\hline \multicolumn{3}{|c|}{ Yield strength $(\mathrm{MD})\left(\mathrm{R}^{2}=0.964\right)$} \\
\hline Independent variable & Parameter & "p" \\
\hline Density & 1.396650 & 0.000456 \\
\hline Independent parameter & -0.405464 & 0.000545 \\
\hline \multicolumn{3}{|c|}{ Yield strength $(\mathrm{TD})\left(\mathrm{R}^{2}=0.991\right)$} \\
\hline Independent variable & Parameter & "p" \\
\hline Density & 1.689987 & 0.000014 \\
\hline Independent parameter & -0.693057 & 0.000016 \\
\hline \multicolumn{3}{|c|}{ Dart impact strength $\left(\mathrm{R}^{2}=0.912\right)$} \\
\hline Independent variable & Parameter & "p" \\
\hline FI & -0.177880 & 0.004263 \\
\hline Independent parameter & -0.005153 & 0.000050 \\
\hline \multicolumn{3}{|c|}{ Haze $\left(\mathrm{R}^{2}=0.974\right)$} \\
\hline Independent variable & Parameter & "p" \\
\hline FI & 11.4019 & 0.006155 \\
\hline Density & 9.5937 & 0.005294 \\
\hline FI*Density & -25.4116 & 0.006155 \\
\hline Independent parameter & -4.4465 & 0.005335 \\
\hline \multicolumn{3}{|c|}{ Gloss $\left(\mathrm{R}^{2}=0.967\right)$} \\
\hline Independent variable & Parameter & "p" \\
\hline FI & 0.37926 & 0.008770 \\
\hline Density & -0.58124 & 0.017156 \\
\hline FI*Density & -3.61556 & 0.013185 \\
\hline Independent parameter & 2.12979 & 0.015896 \\
\hline
\end{tabular}

the molecular weight, so that the polymer resists to the separation which leads to fracture. The model for this property is showed bellow (Equation 3).

$$
\mathrm{EB}=\mathrm{a} * \mathrm{FI}+\mathrm{b} * \text { density }+\mathrm{c}
$$

Stiffness can be express by the flexion elastic module (flexural modulus), which supplies a strain strength measure while forces are applied. The module is the ratio between the applied tension and the resultant deformation. The stiffness increases according to module increases. The molecular weight influence over the stiffness will depend on its relation to the degree of crystallinity and the degree of molecular orientation. For this reason, the stiffness can increase or decrease as the fluidity index (FI) reduces ${ }^{3}$. In the proposed model (Equation 4), the stiffness decreases as the fluidity index increases; this is in accordance to literature data for samples that doesn't present high degree of orientation. Kundu et al. ${ }^{6}$ found an inverse correlation between modulus and MW for polyethylene.

$$
\text { Stiffness }=\mathrm{a} * \mathrm{FI}+\mathrm{b} * \text { density }+\mathrm{c}
$$

Latado et al. ${ }^{3}$ tested many grades of polypropylene and propylene/ ethylene copolymers to develop empirical models in order to predict the stiffness. In this case, the best result obtained for this property is showed in Equation 5

$$
\text { Stiffness }=\frac{\mathrm{a}_{1}}{\mathrm{MW}}+\mathrm{a}_{2} * \mathrm{XS}+\mathrm{a}_{3}
$$

where, $\mathrm{a}_{1}=-1.45 * 10^{5}, \mathrm{a}_{2}=-3.37 * 10^{-2} \mathrm{a}_{3}=2.2530, \mathrm{MW} \rightarrow$ Molecular weight, $\mathrm{XS} \rightarrow$ Xylene solubles (weight percent).

It is important to emphasize that some properties usually assumed to impact the stiffness are not used in the model building. The density is one of them. Consideration has to be given whether the experimental range of variation observed for crystallinity is too narrow, although the degree of crystallinity certainly depends on both XS and MW, which are used as model inputs ${ }^{3}$.

Figures 3-6 show the quality of models fitting to the experimental data and the associated error for ultimate tensile strength, yield strength, elongation at break and stiffness.

\subsection{Vicat, softening point, melting temperature and crystallization temperature}

The Vicat softening point (VP) and melting temperature (Tm) increase strongly with the density increase and FI decrease. As 


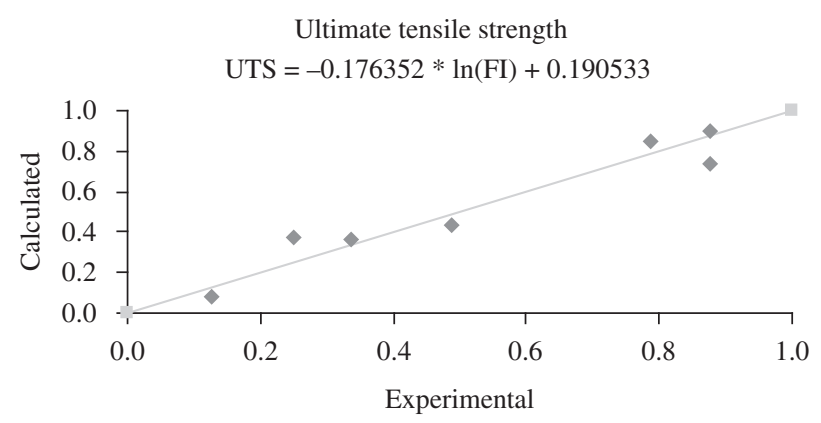

Figure 3. Comparison between experimental values and calculated values for ultimate tensile strength.

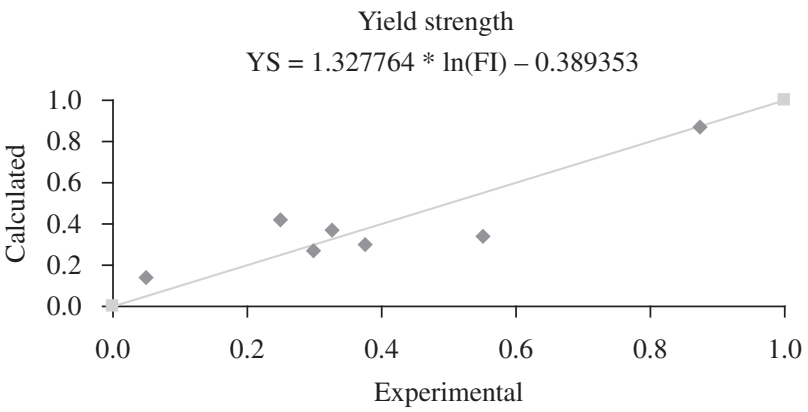

Figure 4. Comparison between experimental values and calculated values for yield strength.

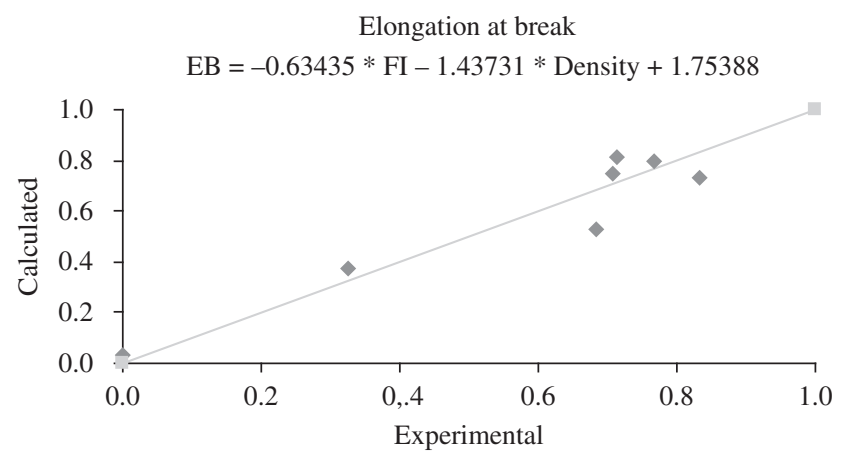

Figure 5. Comparison between experimental values and calculated values for elongation at break.

Stiffness

Stiffness $=0.27123 * \mathrm{MI}+2.02570 *$ Density -1.04289

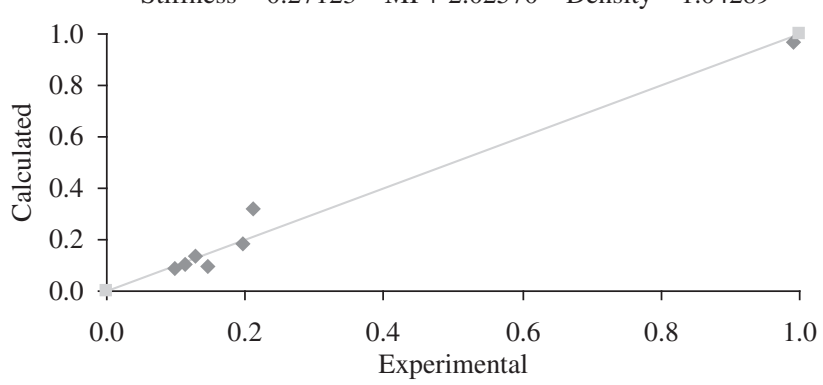

Figure 6. Comparison between experimental values and calculated values for stiffness.

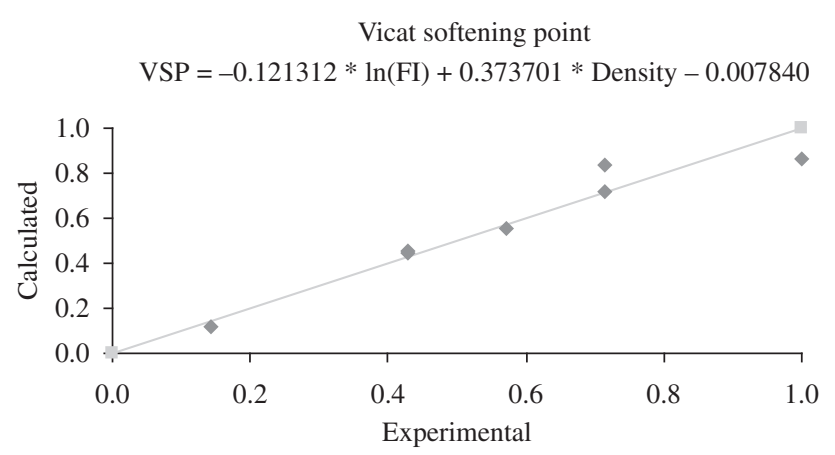

Figure 7. Comparison between experimental values and calculated values for Vicat softening point.

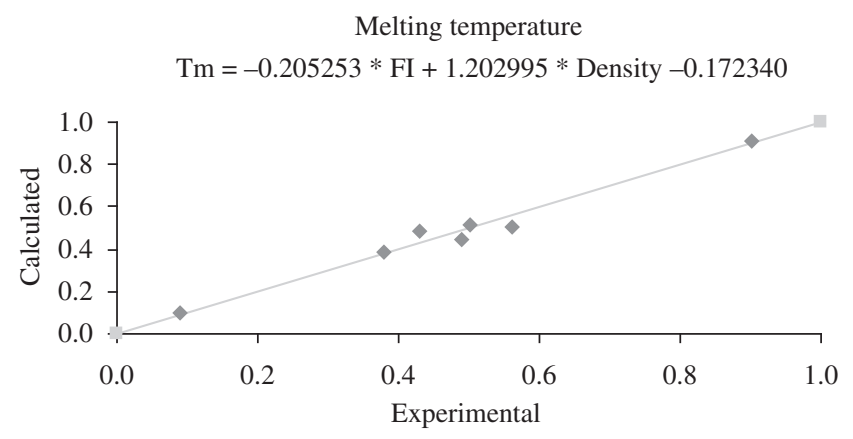

Figure 8. Comparison between experimental values and calculated values for melting temperature.

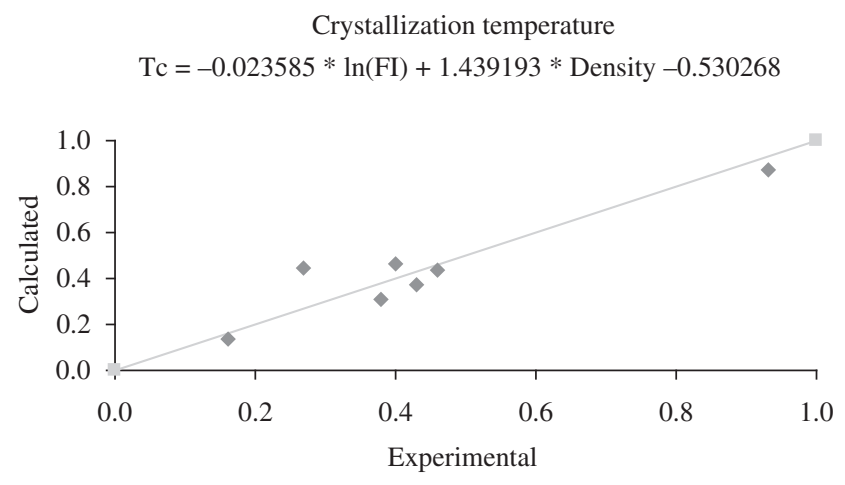

Figure 9. Comparison between experimental values and calculated values for crystallization temperature.

previously mentioned, the density and/or molecular weight increase improve the polymer resistance to the raised temperatures. On the other hand, the wide molecular weight distribution can cause the reduction of this property, because the landslide between polymeric chains is facilitated, reducing the polymer softening temperature. The models found for these properties are given in Equation 6 and Equation 7.

$$
\begin{aligned}
& \mathrm{P}=\mathrm{a} * \ln (\mathrm{FI})+\mathrm{b} * \text { density }+\mathrm{c} \\
& \mathrm{Tm}=\mathrm{a} * \mathrm{FI}+\mathrm{b} * \text { density }+\mathrm{c}
\end{aligned}
$$

The Tm is related to overcoming secondary forces and supporting mobility to the polymeric chains. Thus, the factors that increase secondary forces and stiffness chains will increase the Tm. In this 


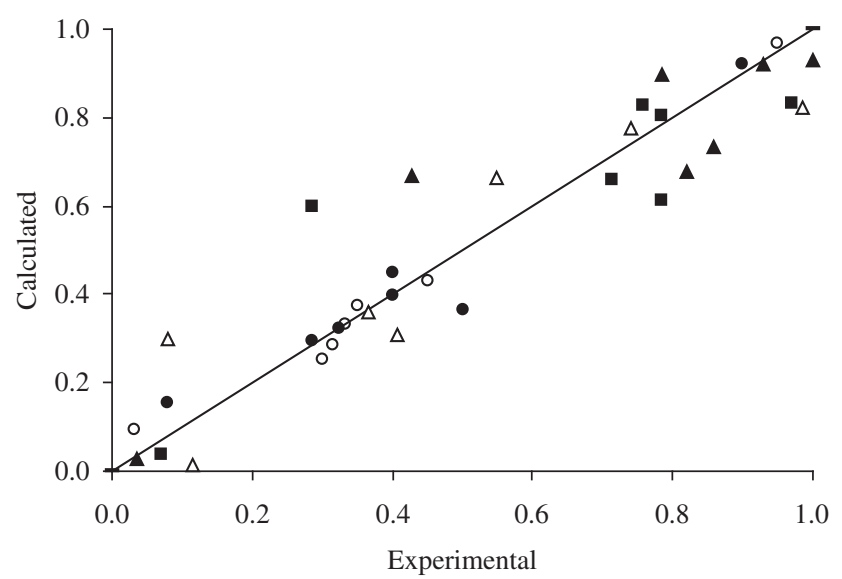

\begin{tabular}{|llc|}
\hline - Reference & $\bullet$ & Yield strength (MD) \\
- Ultimate tensile strength (MD) & $\circ$ & Yield strength (TD) \\
$\Delta \quad$ Ultimate tensile strength (TD) & $\Delta$ & Dart impact strength \\
\hline
\end{tabular}

Figure 10. Comparison between experimental values and calculated values for ultimate tensile strength (MD) and (TD), yield strength (MD) and (TD) and dart impact strength.

sense, the density increase affects the melting temperature. The melting temperature also presented strong and positive correlation with the density. This is due the fact the as the density increases, the forcers between chains increase, raising the necessary energy to polymeric chains mobility. As larger the molecular weight, greater will be the temperature for the beginning of the viscous draining. Thus, samples with larger molecular weight possess larger physical interaction between the chains, causing reduction of the chains flexibility in case of molten polymers. The expected overall trend for homopolymers is such that lower MW polymers are to melt at lower temperatures than higher MW samples.

Polymers which crystallize at high temperatures have a higher density, in comparison to polymers which crystallize at low temperatures. This fact occurs because at high crystallization temperatures, the crystals are more perfectly formed. Moreover, crystallization temperature (Tc) increases when the fluidity index reduces (for crystallized polymers). Polymers with low molecular weight (high MI) have a better mobility, crystallizing at lower temperatures than polymers with higher molecular weight. In the same way, polymers with wider molecular weight distribution will crystallize more easily, because smaller chains move more easily among larger chains, facilitating the crystallization. Thus, the crystallization temperature tends to decrease as the molecular weight distribution widens. The best model found for this property is presented in Equation 8.

$$
\mathrm{Tc}=\mathrm{a} * \ln (\mathrm{FI})+\mathrm{b} * \text { density }+\mathrm{c}
$$

Figures 7-9 show the models fitting to the experimental data and the error associated with vicat softening point, melting temperature and crystallization temperature.

\subsection{Ultimate tensile strength (MD), ultimate tensile strength (TD), yield strength (MD), yield strength (TD) and dart impact strength}

Film tensile mechanical properties and tear strength are correlated to the degree of orientation with respect to the machine direc- tion (MD) and transverse direction (TD). Thus, these properties are much influenced by film production process. Film obtaining process determines properties associated to the molecules orientation, degree of crystallinity, film thickness and imperfections ${ }^{6}$.

In the case of the films ultimate tensile strength, the molecular weight increase tends to increase the polymeric chains orientation during the process; thus, the linking forces between them increase which improvement the MD and TD tensile strength.

The yield strength (MD) and (TD) are strong and positively correlated with density. As explained previously, this probably occurs because of the stronger interaction forces between molecules as the density increases.

The best models results for film tensile mechanical properties were obtained with a simple straight line (Equations 9-12); however, the ultimate tensile strength is correlated with FI and the yield strength is correlated with density.

$$
\begin{aligned}
& \mathrm{UTS}_{(\mathrm{MD})}=\mathrm{a} * \mathrm{FI}+\mathrm{b} \\
& \mathrm{UTS}_{(\mathrm{TD})}=\mathrm{a} * \mathrm{FI}+\mathrm{b} \\
& \mathrm{YS}_{(\mathrm{MD})}=\mathrm{a} * \text { density }+\mathrm{b} \\
& \mathrm{YS}_{(\mathrm{TD})}=\mathrm{a} * \text { density }+\mathrm{b}
\end{aligned}
$$

The dart impact strength (DIS) increases as the FI decreases. It is well known that the impact strength is strongly correlated with weight average molecular weight; in fact, it is basically a function of molecular weight ${ }^{3}$. An increase in the MW tends to increase polymer toughness because the number of the "tie molecules" increases, which improvement the impact strength. On the other hand, in the proposed model (Equation 13) the density didn't present significant influence in dart impact strength. This is due to narrow range of density values used, since all the analyzed resins are low density ones. However, this property can improve as the density decreases because the polymer becomes less rigid.

$$
\text { DIS }=a * \ln (F I)+b
$$

Figure 10 depicts the quality of models fitting to the experimental error associated with ultimate tensile strength (MD) and (TD), yield strength (MD) and (TD) and impact dart strength.

It is important to perceive that the empirical models performance is quite satisfactory.

\subsection{Optical properties (gloss, haze)}

It is a hard task to obtain a satisfactory model involving the optical properties and intrinsic properties (FI and density). The optical properties (gloss, haze) of plastic material are not directly related with chemical structure or molecular weight, but they are mainly determined by the polymer morphology and film surface roughness and additives incorporated. Hence, a deeper study involving the structural and topographical characterization of films through microscopic and spectroscopic methods is a good way to obtain more satisfactory models for these properties.

The final properties evaluated, the correlation coefficients of the models obtained for each end-use property, and the way as each final property is connected to the intrinsic properties (used as inputs in the models) are all resumed in Table 5.

\section{Conclusions}

Empirical models have been developed to predict end-use properties of polyethylene resins. The properties are tensile strength, yield strength, elongation at the break, stiffness, vicat softening 
Table 5. Correlation between intrinsic and end-use properties.

\begin{tabular}{llll}
\hline \multicolumn{1}{c}{ Property } & \multicolumn{1}{c}{ FI $(\uparrow)$} & Density $(\uparrow)$ & R \\
\hline Tensile strength & Decreases & Little influence & 0.960 \\
Yield strength & Little influence & Increases & 0.883 \\
Elongation at break & Decreases & Decreases & 0.952 \\
Stiffness & Increases & Increases & 0.988 \\
Vicat softening point & Decreases & Increases & 0.961 \\
Melting temperature & Decreases & Increases & 0.987 \\
Crystallization temperature & Decreases & Increases & 0.933 \\
Tensile strength MD and TD & Decreases & Little influence & 0.863 (MD) \\
& & & 0.919 (TD) \\
Yield strength MD and TD & Little influence & Increases & $0.964(\mathrm{MD})$ \\
Dart impact strength & & & $0.991(\mathrm{TD})$ \\
\hline
\end{tabular}

temperature, melting temperature, crystallization temperature, dart impact strength, tensile strength (MD) and (TD), yield strength (MD) and (TD), gloss and haze. According to the results presented, tensile strength, elongation at break, vicat softening point, melting temperature, crystallization temperature, tensile strength (MD) and (TD) and dart impact strength decrease as the FI increases. Yield strength, stiffness, vicat softening point, melting temperature, crystallization temperature, yield strength (MD) and (TD) increase as the density increases. The optical properties (gloss, haze) of plastic material are not directly related either to the chemical structure or molecular weight, but they are mainly determined by the polymer morphology. The results presented allow to conclude that final properties can be affected by several factors. Also it is shown that it is possible to model polymer end-use properties as functions of fluidity index and density in a simple manner (except for optical properties) which may be a usual tool to define operating conditions to achieve the final products with desired properties.

\section{Acknowledgments}

The authors would like to acknowledge the State of São Paulo Foundation (Fapesp), Process $\mathrm{N}^{\circ}$ 05/52580-4 and Finep for the financial support and Braskem S/A for supply the polymeric resins.

\section{References}

1. Lu J, Sue H -J, Rieker TP. Dual crystalline texture in HDPE blown films and its implication on mechanical properties. Polymer. 2001; 42(10): 4635-4646.

2. Zhang X, Ajji A, Verilhac J -M. Processing-structure-properties relationship of multilayer films. 1. Structure characterization. Polymer. 2001; 42(19): 8179-8195.

3. Latado A, Embiruçu M, Mattos Neto AG, Pinto JC. Modeling of end-use properties of poly(propylene/ethylene) resins. Polymer Testing. 2001; 20(4): 419-439.

4. Mano EB, editor. Polímeros como materiais de engenharia. revised ed. São Paulo: Blucher; 1991.

6. Nunes RW, Martin JR, Johnson JF. Influence of molecular weight and molecular weight distribution on mechanical properties of polymers. Polymer Engineering and Science. 1982; 22(4): 205-228.

5. Kundu PP, Biswas J, Kim H, Choe S. Influence of film preparation procedures on the crystallinity, morphology and mechanical properties of LLDPE films. European Polymer Journal. 2003; 39(8): 1585-1593. 